\title{
Outcomes of Including Fracture Level in Short- Segment Fixation for Thoracolumbar Fracture Dislocation
}

\author{
Jimmy Jyotinbhai Chokshi ${ }^{1}$, Manish Shah ${ }^{2}$ \\ ${ }^{I}$ Department of Orthopaedics, Civil Hospital, Ahmedabad, India \\ ${ }^{2}$ Department of Orthopaedics, Government Spine Institute, Ahmedabad, India
}

Study Design: This was a prospective study of 50 patients of thoracolumbar fracture dislocation treated at a single institution with short-segment fixation with the inclusion of fracture level.

Purpose: To assess the outcomes of including the fracture level in short-segment fixation for thoracolumbar fracture dislocation. Overview of Literature: Traditionally, thoracolumbar fracture dislocation is treated with long-segment posterior fixation. However, to save motion segments, short-segment fixation has been used instead in many cases of thoracolumbar trauma.

Methods: In this study, 50 patients with thoracolumbar fracture dislocation were treated with short-segment fixation with inclusion of the fracture level; patients with pathological fractures or with a McCormack load-sharing score $>6$ were excluded. The 50 patients were prospectively followed for at least 1 year. The duration of surgery, blood loss, and complications were noted. The Visual Analog Scale (VAS) score was used to measure pain, and the American Spinal Injury Association (ASIA) scale was used to determine the neurological status at follow-up. Preoperative, immediate postoperative, and final follow-up X-rays were used to measure the kyphotic angle using Cobb's method.

Results: The mean age of our patients was 33.4 years, and the male:female ratio was 1.9:1. The mean follow-up period was 18.4 months (range, 12-23 months). Injuries were mainly at the thoracolumbar junction area (T11-L2, 41 cases, 82\%). The average duration of surgery was 94.6 minutes, and the average blood loss was $394.8 \mathrm{~mL}$. Postoperative infection occurred in two cases and implant failure in one case. The kyphosis angle values were as follows: average preoperative, $26.80^{\circ} \pm 14.50^{\circ}$; immediate postoperative, $4.30^{\circ} \pm 8.70^{\circ}$; and final follow-up, $5.50^{\circ} \pm 110^{\circ}$. The ASIA scale and VAS score at final follow-up showed improvement.

Conclusions: Inclusion of the fracture level in short-segment fixation for thoracolumbar fracture dislocation (McCormack load-sharing score $\leq 6$ ) gives good kyphosis correction and correction maintenance. It can also obviate the need for traditional long-segment fixation.

Keywords: Thoracolumbar; Fracture; Dislocation; Short segment; Fixation

\section{Introduction}

Thoracolumbar fracture dislocation due to high-energy trauma is a major cause of disability in adults. The traditional treatment is long-segment posterior transpedicular fixation. However, to save motion segments, short-

Received Mar 16, 2018; Revised Jun 13, 2018; Accepted Jun 19, 2018

Corresponding author: Jimmy Jyotinbhai Chokshi

Department of Orthopaedics, Civil Hospital, Asarwa, Ahmedabad-380016, Gujarat, India

Tel: +91-9099017922, Fax: +91-079-22683421, E-mail: drjimmychokshi@gmail.com 
segment fixation has been used instead in many cases of thoracolumbar trauma [1-4]. A few studies have reported the treatment of thoracolumbar fracture dislocation with short-segment fixation, but none have discussed the inclusion of fracture level for fixation [5-9]. Other studies have shown that biomechanical stability of a construct increases by inserting screws at the fracture level [10]. Hence, we conducted this study to analyze the outcomes of including the fracture level in short-segment fixation for thoracolumbar fracture dislocation.

\section{Materials and Methods}

Approval from the ethical committee of Civil Hospital, Ahmedabad, India was taken for conducting the study (IRB approval no is 14-03-214). Between April 2014 and March 2016, we prospectively followed 50 patients with thoracolumbar fracture dislocation treated with shortsegment instrumentation and fusion with inclusion of fracture vertebra; patients with pathological fractures or a McCormack load-sharing score $>6$ were excluded. X-rays and magnetic resonance imaging were used for fracture evaluation and to measure the preoperative kyphotic angle using Cobb's method.

Surgery was performed by a single senior spine surgeon, and the same instrumentation was used in all cases. Decompression was performed when indicated. Fusion was performed using locally harvested autologous bone grafts after meticulous creation of a fusion bed. All patients began rehabilitation from day 2 postoperatively and were provided braces for 3 months. The patients were followed for at least 1 year.

The duration of surgery, blood loss, and complications were noted. The American Spinal Injury Association (ASIA) scale was used to record the neurological status of each patient at follow-up. The Visual Analog Scale (VAS) score was used to measure pain. Immediate postoperative and final follow-up X-rays were used to again measure the kyphotic angle using Cobb's method. During follow-up, additional X-rays were obtained, and investigations were performed in case of any complications.

\section{Results}

The mean age of the 50 patients was 33.4 years (range, 18-68 years), and the male:female ratio was 1.9:1. In the majority of cases (33 cases, 66\%), the mode of injury was determined to be a fall from a height, whereas in the re-

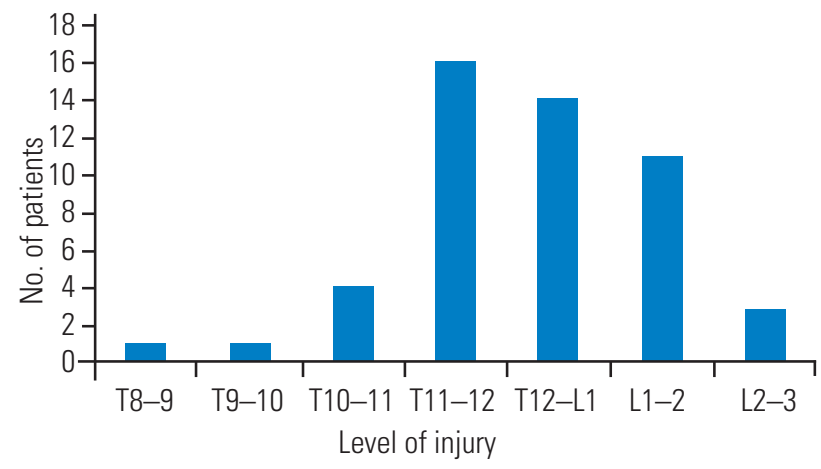

Fig. 1. Level of injury.
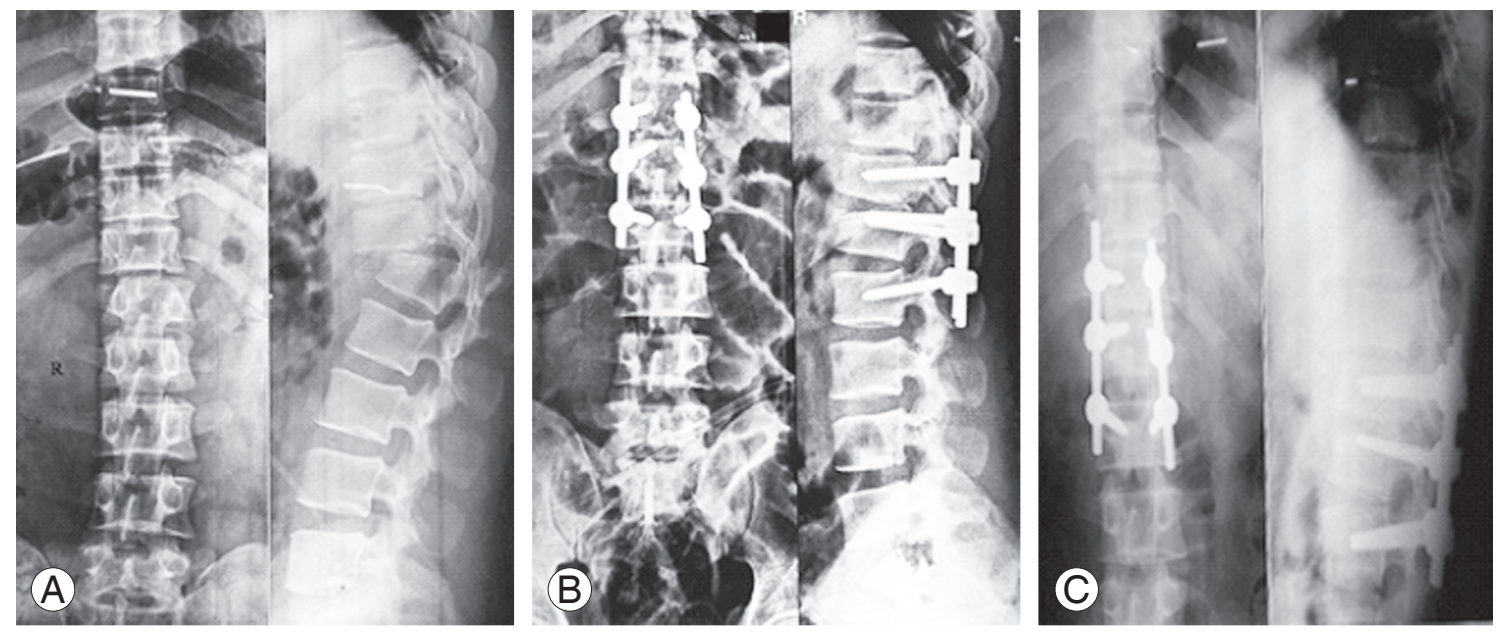

Fig. 2. Surgical case. (A) Preoperative X-ray showing T12-L1 fracture dislocation. (B) Immediate postoperative X-ray showing good correction. (C) Final follow-up X-ray showing maintenance of correction. 
maining cases (17 cases, 34\%), it was determined to be a road traffic accident. With regard to neurological status, 34 patients (68\%) were ASIA A, nine (18\%) were ASIA B, six (12\%) were ASIA C, and one (2\%) was ASIA D. Injuries were mainly at the thoracolumbar junction area (T11L2, 41 cases, 82\%), and the remaining (nine cases, 18\%) were in the remaining thoracolumbar spine (Fig. 1).

The average duration of surgery was 94.6 minutes, and the average blood loss was $394.8 \mathrm{~mL}$. Postoperative infection occurred in two cases, and implant failure occurred in one case.

All patients were followed for at least 1 year; the mean follow-up period was 18.4 months (range, 12-23 months). The kyphosis angle values were as follows: average preoperative, $26.80^{\circ} \pm 14.50^{\circ}$; immediate postoperative, $4.30^{\circ} \pm 8.70^{\circ}$; and final follow-up, $5.50^{\circ} \pm 110^{\circ}$ (Fig. 2). ASIA scale values at final follow-up showed improvement (Fig. 3). The VAS score improved from 8.6 to 2.4 at final follow-up.

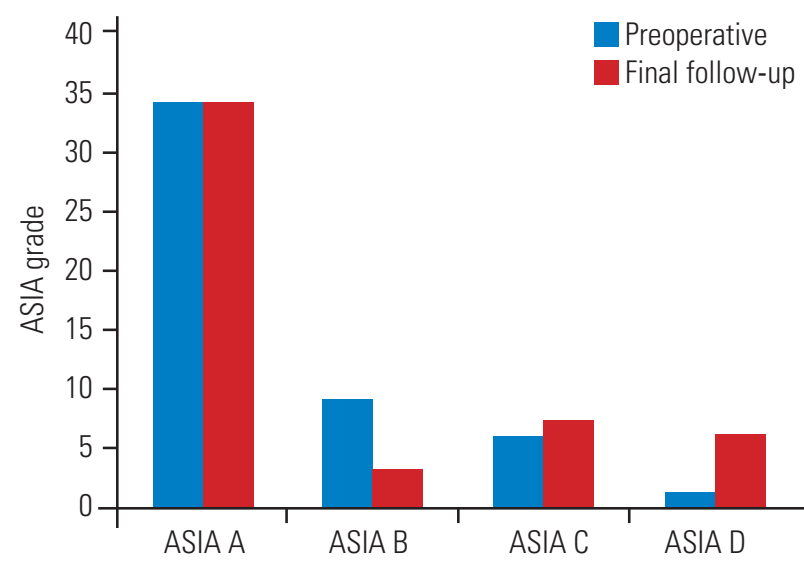

Fig. 3. ASIA grade. ASIA, American Spinal Injury Association.

\section{Discussion}

Thoracolumbar fractures are the most common injuries of the spine; they constitute more than $50 \%$ of all traumatic spine cases [11]. However, fracture dislocations are rare, constituting only $<3 \%$ cases [12]. Thoracolumbar fracture dislocations are a cause of significant morbidity and mortality in patients.

As per the Thoracolumbar Injury Classification and Severity Score [13], injury to the posterior ligament complex is highly unstable and the associated neurological injury makes surgery inevitable. The traditional treatment is long-segment fixation. However, this procedure causes loss of motion segments. Therefore, to save motion segments, short-segment fixation was tried, but it was associated with a high complication rate. Yu et al. [14] treated thoracolumbar fracture dislocations with short-segment fixation and had a complication rate of $15 \%$ for loss of reduction, $20 \%$ for implant failure, $10 \%$ for pseudoarthrosis, and $25 \%$ for poor initial postoperative reduction. Comparatively, our study had fewer complications (Table 1). We had one case of implant failure that was treated with extension of fixation, one case of superficial infection that was treated with antibiotics and dressings, and one case of deep infection that was treated with debridement and antibiotics. Eventually, all three cases achieved fusion. In this

Table 1. Complications

\begin{tabular}{lcl} 
Complications & $\begin{array}{c}\text { No. of } \\
\text { patients }\end{array}$ & \multicolumn{1}{c}{ Treatment } \\
\hline Implant failure & 1 & Extension of fixation \\
\hline Superficial infection & 1 & Antibiotics and dressings \\
\hline Deep infection & 1 & Debridement and antibiotics \\
\hline
\end{tabular}

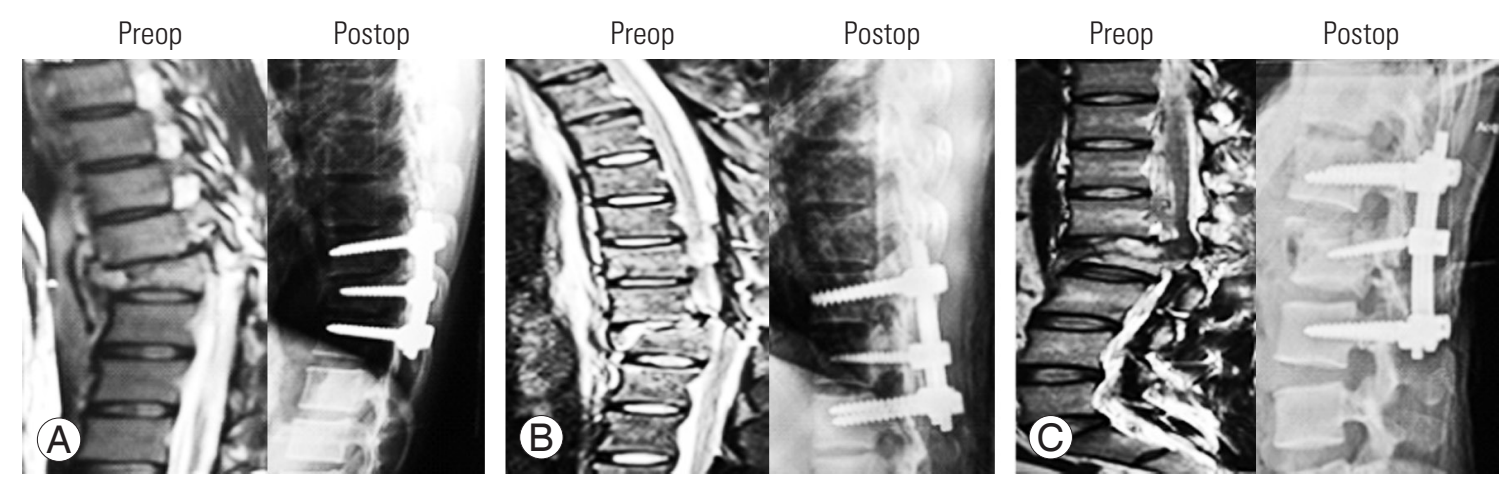

Fig. 4. Kyphosis correction achieved at different levels: (A) T9-10; (B) T10-11; (C) L1-2. Preop, preoperative; Postop, postoperative. 
study, we used locally harvested bone grafts for fusion and consistently achieved good results; there was no requirement for other autografts, allografts, or bone graft substitutes. There were no cases of poor initial reduction or loss of reduction (Fig. 4). The better kyphosis correction and maintenance that was achieved may be because of the stronger three-point support provided by the inclusion of fracture vertebra in the construct. Studies by Guven et al. [15] and Mahar et al. [10] have also concluded that fracture-level screw insertion increases stability, helps in fracture reduction and kyphosis correction, and decreases the chances of correction failure, especially with shortsegment constructs. We included only patients with a McCormack load-sharing score of $\leq 6$ because they needed no anterior reconstruction.

Dobran et al. [16] have shown that including the fracture level in short-segment fixation to treat thoracolumbar junction fractures results in kyphosis correction and maintenance similar to that in the case of long-segment fixation, with similar neurological outcomes. Besides the obvious advantages of shorter incisions, lesser dissection, fewer screws, lower cost, and lesser chances of infection, short-segment fixation results in saving the motion segments.

Our study has certain limitations. First, the number of patients was small, and they all were from the same institution. Second, computed tomography scans were not performed to check the fusion status because of nonavailability of appointments at our high-volume institution. We plan to improve upon these shortcomings in future studies.

\section{Conclusions}

The results of our study suggested that including the fracture level in short-segment fixation for thoracolumbar fracture dislocation (with a McCormack load-sharing score $\leq 6)$ achieves good kyphosis correction and correction maintenance. It also obviates the need for longsegment fixation.

\section{Conflict of Interest}

No potential conflict of interest relevant to this article was reported.

\section{References}

1. Knop C, Bastian L, Lange U, Oeser M, Zdichavsky $\mathrm{M}$, Blauth M. Complications in surgical treatment of thoracolumbar injuries. Eur Spine J 2002;11:214-26.

2. Parker JW, Lane JR, Karaikovic EE, Gaines RW. Successful short-segment instrumentation and fusion for thoracolumbar spine fractures: a consecutive 41/2year series. Spine (Phila Pa 1976) 2000;25:1157-70.

3. Tezeren G, Kuru I. Posterior fixation of thoracolumbar burst fracture: short-segment pedicle fixation versus long-segment instrumentation. J Spinal Disord Tech 2005;18:485-8.

4. Altay M, Ozkurt B, Aktekin CN, Ozturk AM, Dogan O, Tabak AY. Treatment of unstable thoracolumbar junction burst fractures with short- or long-segment posterior fixation in Magerl type a fractures. Eur Spine J 2007;16:1145-55.

5. Bohlman HH. Treatment of fractures and dislocations of the thoracic and lumbar spine. J Bone Joint Surg Am 1985;67:165-9.

6. Bradford DS, Akbarnia BA, Winter RB, Seljeskog EL. Surgical stabilization of fracture and fracture dislocations of the thoracic spine. Spine 1977;2:185-96.

7. Jacobs RR, Asher MA, Snider RK. Thoracolumbar spinal injuries: a comparative study of recumbent and operative treatment in 100 patients. Spine (Phila Pa 1976) 1980;5:463-77.

8. Gertzbein SD, Court-Brown CM. Flexion-distraction injuries of the lumbar spine: mechanisms of injury and classification. Clin Orthop Relat Res 1988;227:52-60.

9. Bradford DS, McBride GG. Surgical management of thoracolumbar spine fractures with incomplete neurologic deficits. Clin Orthop Relat Res 1987;(218):201-16.

10. Mahar A, Kim C, Wedemeyer M, et al. Short-segment fixation of lumbar burst fractures using pedicle fixation at the level of the fracture. Spine (Phila $\mathrm{Pa}$ 1976) 2007;32:1503-7.

11. Patel AA, Dailey A, Brodke DS, et al. Thoracolumbar spine trauma classification: the Thoracolumbar Injury Classification and Severity Score system and case examples. J Neurosurg Spine 2009;10:201-6.

12. Denis F. Spinal instability as defined by the threecolumn spine concept in acute spinal trauma. Clin Orthop Relat Res 1984;(189):65-76. 
13. Vaccaro AR, Lehman RA Jr, Hurlbert RJ, et al. A new classification of thoracolumbar injuries: the importance of injury morphology, the integrity of the posterior ligamentous complex, and neurologic status. Spine (Phila Pa 1976) 2005;30:2325-33.

14. Yu SW, Fang KF, Tseng IC, Chiu YL, Chen YJ, Chen WJ. Surgical outcomes of short-segment fixation for thoracolumbar fracture dislocation. Chang Gung Med J 2002;25:253-9.
15. Guven O, Kocaoglu B, Bezer M, Aydin N, Nalbantoglu U. The use of screw at the fracture level in the treatment of thoracolumbar burst fractures. J Spinal Disord Tech 2009;22:417-21.

16. Dobran M, Nasi D, Brunozzi D, et al. Treatment of unstable thoracolumbar junction fractures: shortsegment pedicle fixation with inclusion of the fracture level versus long-segment instrumentation. Acta Neurochir (Wien) 2016;158:1883-9. 